\title{
Frequency of eyewitness identification in criminal cases: A survey of prosecutors
}

\author{
ALVIN G. GOLDSTEIN, JUNE E. CHANCE, and GREGORY R. SCHNELLER \\ University of Missouri, Columbia, Missouri
}

\begin{abstract}
One hundred fifty-seven prosecutors in 30 states were asked to estimate how often they process criminal cases in which eyewitness identification is of critical importance, the total number of felony cases processed each year by their staffs, and the size and composition (urban or rural) of the populations serviced by their departments. Approximately $36 \%$ (57) of the prosecutors responded. From their replies it was calculated that eyewitness cases constituted about 3\% (median) of their felony cases. Thus, assuming approximately 2,570,000 arrests in the U.S. each year, about 77,000 individuals are suspects in cases in which the only critical evidence is eyewitness identification.
\end{abstract}

The purpose of the research reported here was to obtain an estimate of the annual frequency of criminal cases in the United States in which eyewitness (EW) identification is of central importance. The term criminal cases refers to the number of suspects formally charged by a state prosecutor with the commission of a criminal action on the basis of direct (eyewitness) evidence, without regard to eventual case disposition. Thus, "cases" are those that went to trial as well as those dismissed after pretrial hearings.

Since 1908, when Hugo Munsterberg's prescient volume, On the Witness Stand, was published, much evidence has accumulated to support the conclusion that eyewitnesses often make errors when they identify a suspect as the perpetrator of a crime. Some of this evidence originates in the psychological laboratory and some from other controlled methods of obtaining empirical data (e.g., field experiments), but a respectable amount of evidence also originates from within the justice system itself. For example, extensive media coverage of two recent cases of mistaken identity-those of Father Pagano in Wilmington, Delaware (Buckhout, 1979), and Lenell Geter in Dallas (Buckhout, 1984)-clearly demonstrates that calamity can result when EW testimony is the sole basis for charging a person with a crime (see Borchard, 1932; Brandon \& Davies, 1973; Huff, Rattner, \& Sagarin, 1986, pp. 524-527; Wall, 1965, for reviews of EW errors).

Nonetheless, notorious cases do not offer a controlled basis on which to estimate the number of wrongful convictions, because such cases get into newspaper headlines only when someone is freed after conviction and imprisonment on the basis of new evidence. Those individuals still

A modified version of this report was presented at the Midwestern Psychological Association meeting in Chicago, May 1987. This research was funded by a grant from the Research Council of the Graduate School, University of Missouri, Columbia. The authors are grateful for the help of Bruce Sales, Jim Alfini, Gordon Berment, Ingo Keilitz, and Betty Wilson. The authors' address is Department of Psychology, 210 McAlester Hall, University of Missouri, Columbia, MO 65211. imprisoned for alleged criminal activity because they are unable to prove their innocence are never counted.

Eyewitness identification testimony is widely accepted in the courts. It is often the only evidence available in certain kinds of crimes. Moreover, many members of the criminal justice system believe that errors of identification are really quite rare, and therefore they have little reason to refrain from prosecuting when the only evidence is EW testimony.

But the empirical facts about the validity of EW testimony, especially EW identification, are very disturbing. Aside from those few well-publicized cases of mistaken identity offering clear evidence that sometimes real witnesses make grave errors and innocent people are either imprisoned or executed (Wall, 1965), the outcomes of nearly all controlled psychological investigations employing realistic simulated crimes or staged events strongly suggest that identification errors in the real world may be relatively frequent, rather than rare. Two examples from the psychological literature will suffice to show how poorly face recognition serves as a method of identifying a stranger seen earlier for a brief period of time.

In a field experiment (Brigham, Maass, Snyder, \& Spaulding, 1982), 73 convenience store clerks were asked to select photographs of "customers" who, 2 h earlier, had spent about 4 min interacting with the clerks by paying for their purchases with a large number of pennies and then asking for directions to either a bus station or the local airport. The clerks' overall rate of accurate identification was $34 \%$. Omitting those who did not attempt identification, identifications were $47 \%$ correct. Fortyfive percent of the clerks identified a picture of the wrong person (i.e., a false alarm). Interestingly, Brigham et al. had initially planned to wait $24 \mathrm{~h}$ before testing face recognition, but pilot research indicated chance-level performance after $24 \mathrm{~h}$ (Brigham et al., 1982, p. 676). Using a somewhat different method, Wells and his associates (Lindsay, Wells, \& Rumpel, 1981; Wells, Lindsay, \& Ferguson, 1979) placed a "witness" in a room with one other person (the confederate) for less than $1 \mathrm{~min}$ before 
the confederate blatantly took a calculator from a table and ran out of the room. By manipulating both the length of time the thief interacted with the witness and the amount of hair visible under a stocking cap. Correct identification of the thief from a photo lineup was varied from a low of $33 \%$ (with $67 \%$ false alarms) to a high of $73 \%$ (27\% false alarms), depending on the experimental conditions. In a slightly different version of this theft simulation, only $58 \%$ of the witnesses successfully identified the thief from a subsequent photo lineup, $20 \%$ made inaccurate choices, and $21 \%$ did not identify anyone as the thief. Many other ecologically relevant experiments (e.g., Leippe, Wells, \& Ostrom, 1978; Loftus \& Greene, 1980; Malpass \& Devine, 1981; Murray \& Wells, 1982; Wells, $1984)$ support the conclusion that EW errors are not rare events. Since these identification errors occur reliably in situations perceived by witnesses as being unquestionably real, and under testing conditions largely free of the biases often inherent in procedures used by police to question witnesses, it is reasonable to hypothesize that identification errors may occur in the criminal justice system at rates similar to-or even higher than-those revealed by the research studies.

Even granting that $\mathrm{EW}$ identification errors occur more frequently than was formerly thought, some legal observers would still argue that not enough trials are decided by $\mathrm{EW}$ identification testimony alone to warrant a change in criminal justice procedures. How justified is the belief held in legal circles that "pure" cases or cases hinging largely on EW identification evidence are rare?

An extensive literature search located only three relevant, but not definitive, citations. In a commentary on lineup composition (Sobel, 1985, chap. 10), a jurist stated that "in the District of Columbia, as many as twenty lineups are held two evenings a week," suggesting that many cases in the District might be dependent on EW identification. Huff et al. (1986, p. 524) estimated that $60 \%$ of 500 cases they had documented to be pure wrongful convictions (i.e., felony convictions later set aside because of a confession, new evidence, etc.) were caused by $\mathrm{EW}$ misidentifications. In addition, a survey of the frequency of wrongful conviction carried out by these same authors, showed that 8 out of 10 respondents (judges, DAs, police) ranked witness error, including EW error, as the most frequent type of error leading to false conviction. Finally, Loh (1981, p. 686) estimated that EW evidence is used in about $5 \%$ of all criminal trials.

Other avenues also proved fruitless. Although many federal and state agencies publish crime-report data, none classify criminal cases according to the kind of evidence involved in the case. Moreover, there is no national clearinghouse for data generated by the lower, or trial, courts. Finally, a comprehensive survey of EW case frequency should include all arraignments, not just court trials. As a member of the National Center for State Courts observed (Keilitz, personal communication, January 20, 1986), only judges and prosecutors had access to the data we needed, since detailed, systematic, empirical data con- cerning the frequency of EW cases were unavailable from any published source in the United States.

\section{METHOD}

A single-page questionnaire, to be answered anonymously, was mailed to 157 district attorneys (DAs) in 30 states and Washington, D.C. Each questionnaire was accompanied by a letter explaining the purpose of the study and a stamped return envelope.

The questionnaire asked for estimates of (1) the number of cases per year in which EW identification testimony was the principal evidence against the defendant (2) the total number of felony cases per year processed by the DA's office, and (3) the population size and composition (rural or urban) of the area served by the DA's staff. In a pilot study, a series of more detailed questions in which the importance or centrality of EW testimony was varied (e.g., EW only, EW with some weak physical evidence) had elicited few useful replies and many complaints from respondents. Thus the questionnaire we finally sent to DAs was very narrow in scope and was designed to elicit frequency counts of cases in which EW identification was the crucial, if not the sole, evidence in the case. (It is almost impossible to find cases wholly devoid of other evidence. Even the absence of certain kinds of evidence is evidence, and almost every suspect has an alibi, although it may be worthless in the eyes of the jury.)

Prosecutors with offices in 67 cities with populations over 100,000 received questionnaires. Included in that group were DAs in 22 of the 25 largest U.S. cities (populations of 541,000 to over 7 million). The remaining 90 questionnaires were mailed to DAs with offices in cities with populations below $100,000 .^{1}$ The 157 DAs in the sample represent about $5 \%$ of the 2,850 DAs in the United States. Thirty-four states were included in the survey: seven Eastern, seven Southern, six Midwestern, and nine Western states plus Hawaii.

\section{RESULTS AND DISCUSSION}

A summary of the replies from 53 prosecutors who returned their questionnaires is shown in Table 1. Some of the 57 replies were unusable, or partially so; therefore, 45 returns were used in most of the analyses reported here. The percentage return is not unusual for mailed questionnaires. No prosecutor replied from Arkansas, Massachusetts, Mississippi, New Mexico, or New Jersey. These failures to reply are discussed more fully later.

The median percentage of felony cases in which EW evidence was considered crucial was $3 \% .^{2}$ About $7 \%$ of the respondents denied ever prosecuting a "pure" EW case, and an additional $18 \%$ said that they process less than one such case per year. About $35 \%$ of the respondents process from $1 \%$ to $5 \% \mathrm{EW}$ cases each year, and $40 \%$ prosecute between $5 \%$ and $38 \%$ EW cases annually.

Twelve respondents returned unusable questionnaires. In two instances (both large urban areas in California), they refused to answer because they wanted further information about the use the researchers were going to make of the data. In two additional instances, the replies could not be deciphered. Something can be learned, however, from the replies of the eight remaining respondents. These prosecutors stated that they were unable to estimate the number of $\mathrm{EW}$ cases because of the large number of cases handled by their staffs each year. The total annual caseloads of these eight DAs varied from 1,753 (Michigan) to 60,000 (New York City). Except for the Michigan DA, all DAs in this group had case loads 
Table 1

Prosecutors' Replies to Questionnaire, Listed Alphabetically by Location

\begin{tabular}{|c|c|c|c|c|}
\hline Location & $\begin{array}{c}\text { No. of } \\
\text { Eyewitness } \\
\text { Cases }\end{array}$ & $\begin{array}{l}\text { No. of } \\
\text { Felony } \\
\text { Cases } \\
\end{array}$ & $\begin{array}{c}\% \\
\begin{array}{c}\text { Eyewitness } \\
\text { Cases }\end{array} \\
\end{array}$ & Population* \\
\hline Alabama & 10 & 400 & 2.5 & a \\
\hline Alabama & 200 & 5,000 & 4 & d \\
\hline Alabama & 3 & 1,000 & $<1$ & a \\
\hline California & omitted & 60,000 & - & b \\
\hline Colorado & 15 & 1,200 & 1.25 & d \\
\hline Florida & 1,044 & 36,000 & $<3$ & b \\
\hline Florida & 10 & 5,500 & $<1$ & c \\
\hline Georgia & 150 & 5,000 & 3 & c \\
\hline Georgia & 200 & 1,200 & 15 & c \\
\hline Hawaii & 365 & 2,437 & 15 & d \\
\hline Hawaii & 76 & 3,780 & 2 & c \\
\hline Illinois & 20 & 650 & 3 & c \\
\hline Illinois & 30 & 350 & 8 & $\mathbf{a}$ \\
\hline Illinois & 15 & 400 & 4 & d \\
\hline Indiana & 25 & 350 & 7 & d \\
\hline Indiana & 170 & 1,000 & 17 & d \\
\hline Kansas & $<10$ & 1,700 & $<1$ & c \\
\hline Kentucky & $<20$ & 150 & 13 & d \\
\hline Kentucky & 3 & 103 & 3 & $\mathbf{a}$ \\
\hline Kentucky & 0 & $300+$ & 0 & d \\
\hline Kentucky & 50 & 500 & 10 & d \\
\hline Louisiana & 52 & 6,512 & $<1$ & c \\
\hline Maine & 32 & 325 & 10 & a \\
\hline Maine & 0 & 1,000 & 0 & d \\
\hline Michigan & omitted & 832 & - & d \\
\hline Michigan & omitted & 1,753 & - & d \\
\hline Maryland & 0 & 150 & 0 & d \\
\hline Maryland & omitted & 5,152 & - & c \\
\hline Maryland & $<10$ & 1,375 & $<1$ & e \\
\hline Maryland & omitted & 7,100 & - & - \\
\hline Montana & $<10$ & 480 & 2 & d \\
\hline Missouri & 70 & 400 & 17 & c \\
\hline Missouri & omitted & 5,144 & - & c \\
\hline Missouri & 20 & 400 & 5 & d \\
\hline Missouri & 70 & 1,800 & 4 & c \\
\hline Missouri & 5 & 1,300 & $<1$ & d \\
\hline Missouri & $<10$ & 348 & 3 & a \\
\hline Nevada & 37 & 6,786 & $<1$ & c \\
\hline New York City & 7,000 & 20,000 & 35 & b \\
\hline New York City & 195 & 2,089 & 9 & d \\
\hline New York City & omitted & 17,000 & - & b \\
\hline New York & 1,330 & 3,500 & 38 & c \\
\hline Oklahoma & $<5$ & 7,000 & $<1$ & c \\
\hline Oregon & 175 & 6,000 & 3 & c \\
\hline Pennsylvania & 2,902 & 10,750 & 27 & e \\
\hline Tennessee & $<25$ & 950 & 2 & a \\
\hline Tennessee & omitted & 8,500 & - & c \\
\hline Texas & 250 & 1,000 & 25 & c \\
\hline No Postmark & 22 & 900 & 2 & d \\
\hline No Postmark & 800 & 4,000 & 20 & $\mathrm{c}$ \\
\hline No Postmark & 800 & 4,000 & 20 & c \\
\hline No Postmark & 300 & 3,000 & 10 & c \\
\hline No Postmark & 75 & 500 & 15 & $\mathbf{a}$ \\
\hline
\end{tabular}

Note $-* a=$ mostly rural; $b=$ mostly urban, over 3 million; $\mathrm{c}=$ mostly urban, less than 1 million; $d=$ mixed urban and rural; $e=$ other.

in excess of 3,000 per year. Because cases are not classified or recorded according to type of evidence, DAs with heavy case loads are understandably reluctant to estimate EW case frequency. Thus, we were unable to obtain data from several of the large city prosecutors, who were most likely to have had the greatest absolute number of EW cases. The inaccessibility of the EW data is unfortunate.
If large urban areas with a high incidence of serious crime produce more than their share of EW cases, our data will underestimate the frequency of EW cases. This speculation deserves further research, especially since the 3 respondents who reported 0 as the actual frequency of EW cases are DAs in Kentucky, Maine, and Maryland, and each is located in a mixed urban and rural area having very few felony cases each year. Two of these 3 DAs rank 53rd and 54th (out of 57) in our sample in total number of felony cases handled per annum.

A rough estimate of the number of individuals who are arrested on criminal charges on the basis of EW evidence can be obtained if we take the obtained median (3\%) and apply it to the annual total number of arrests for major crimes in the United States. According to the FBI's National Crime Information Service (Uniform Crime Reports for the United States, 1987), there were 2,577,100 arrests for index crimes during 1986 . Thus, using the $3 \%$ estimate, about 77,313 people were arrested on the basis of eyewitness identification. ${ }^{3}$

Another difficulty encountered in attempting to obtain an accurate estimate of the number of $\mathrm{EW}$ cases is that most felony cases do not go to trial but are disposed of through plea bargaining, a process that essentially involves an admission of guilt. Presumably, DAs excluded pleabargained EW cases from their estimates of EW cases if they followed the instructions contained in the introductory statement to the questionnaire: "Confine your estimates to those cases where the defendant did not confess to the crime."

Is our sample representative of DAs in the United States? It is extremely difficult to answer that question, except to emphasize that DAs in both large urban areas and much smaller rural areas did not return their questionnaires. Although crime rates in large cities and small towns may or may not be equal, depending on the type of crime and other factors (see Uniform Crime Reports for the United States, 1987, pp. 147-150), the total frequency of reported crime does differ radically between heavily populated cities and rural areas. Thus, an enormous number of crimes were unaccounted for when DAs in, for example, New Jersey, Massachusetts, three of the five boroughs of New York City, most of Texas, and almost all of Maryland did not reply to our questionnaire. In comparison, only a fraction of that number of criminal cases were "lost" when DAs in small communities did not return their questionnaires.

We draw several conclusions from these data. First, every year more than 77,000 people in the United States are accused of crimes by eyewitnesses, and in an unspecified but presumably large number of instances $\mathrm{EW}$ evidence is either the only evidence or the most critical evidence linking the suspect to the crime. Second, instead of asserting that only a tiny fraction of all criminal cases result in a mistaken-identity conviction, it is now more appropriate, pending new research-based information on the question of EW case frequency, to use the 77,000 figure-derived by applying the median percentage of EW cases $(3 \%)$ to the annual number of arrests for major 
crimes-as the base for calculating the judicial system's possible rate of misidentification. Third, because the number of EW cases is substantial, it is clearly in everyone's best interest to continue research on the problems of $\mathrm{EW}$ reliability. Every time we put the wrong person in jail we miss the chance to put the actual criminal behind bars; every time the system spends its energies on trials and hearings that should never have been called in the first place, all citizens are made poorer.

Fourth, now that we have presented evidence that suggests that EW cases are not rare but occur more or less frequently, depending on factors not yet clarified, the American criminal justice system should show more than academic interest in the results of Great Britain's Devlin Committee report. This committee, commissioned by the British House of Commons to look into the reasons for a number of miscarriages of justice, offered the following bit of wisdom:

We do however wish to ensure that in ordinary cases prosecutions are not brought on eyewitness evidence only and that, if brought, they will fail. We think they ought to fail, since in our opinion it is only in exceptional cases that identification evidence is by itself sufficiently reliable to exclude reasonable doubt about guilt. (Devlin, 1976, p. 149-150)

The committee went on to recommend that the trial court judge direct the jury to use caution in eyewitness cases unless the "eyewitness evidence is supported by substantial evidence of another sort"' (Devlin, 1976, p. 150). The appointment of the Devlin Committee in Great Britain to investigate causes of wrongful conviction brought about by errors of identification stands in sharp contrast to the American criminal justice system's almost hostile attitude toward any suggestion that eyewitness testimony may be a seriously faulted method of obtaining impartial information. The disparity between the two countries may even be greater than it appears: American crime rates are grossly greater than British crime rates, and since $80 \%$ of all the worlds' trials take place in the United States (Horowitz \& Willging, 1984, p. 166), the absolute number of trials in England has to be minuscule compared with the number of trials in the United States. Yet Great Britain has not taken the position, often espoused here, that the eyewitness problem is too small to constitute an important legal issue. ${ }^{4}$

\section{REFERENCES}

BorChARD, E. M. (1932). Convicting the innocent: Errors of criminal justice. New Haven, CT: Yale University Press.

BRANDON, R., \& DAviEs, C. (1973). Wrongful imprisonment: Mistaken convictions and their consequences. London: George Allen \& Unwin.

Brigham, J. C., MaAss, A., Snyder, L. D., \& Spaulding, K. (1982). Accuracy of eyewitness identifications in a field setting. Journal of Personality \& Social Psychology, 42, 673-681.

Buckнout, R. (1979). The mistaken seven: Eyewitness identification in the case of Delaware v. Father Bernard T. Pagano. Social Action \& the Law, 5, 35-44.

BuckHout, R. (1984). Double mistaken identification in Dallas: Texas v. Lenell Geter and Anthony Williams. Social Action \& the Law, 10, 3-9.
Devlin, Honorable L. P. (1976). Report to the Secretary of State for the Home Department of the Departmental Committee on evidence of identification in criminal cases. London: Her Majesty's Stationery Office.

Horowitz, I. A., \& Willging, T. E. (1984). The psychology of law: Integrations and applications. Boston: Little, Brown.

Huff, C. R., RATtNer, A., SAgARIN, E. (1986). Guilty until proved innocent: Wrongful conviction and public policy. Crime \& Delinquency, 32, 518-544.

LeipPe, M. R., Wells, G. L., \& Ostrom, T. M. (1978). Crime seriousness as a determinant of accuracy in eyewitness identification. Journal of Applied Psychology, 63, 345-351.

Lindsay, R. C., L., Wells, G. L., \& Rumpel, C. M. (1981). Can people detect eyewitness-identification accuracy within and across situations? Journal of Applied Psychology, 66, 79-89.

LofTus, E. F., \& GREeNE, E. (1980). Warning: Even memory for faces may be contagious. Law \& Human Behavior, 4, 323-334.

LoH, W. D. (1981). Psychological research: Past and present. Michigan Law Review, 79, 659-707.

Malpass, R., \& Devine, P. (1981). Eyewitness identification: Lineup instructions and absence of the offender. Journal of Applied Psychology, 66, 482-489.

MUNSTERBERG, H. (1908). On the witness stand: Essays on psychology and crime. New York: Boardman.

MurRay, D. M., \& Wells, G. L. (1982). Does knowledge that a crime was staged affect eyewitness performance? Journal of Applied Social Psychology, 12, 43-53.

Sobel, N. R. (1985). Eyewitness identification: Legal and practical problems. New York: Boardman.

Uniform Crime Reports for the United States (July 25, 1987). Washington, DC: FBI, U.S. Department of Justice.

WALL, P. M. (1965). Eyewitness identification in criminal cases. Springfield, IL: Charles C. Thomas.

Wells, G. L. (1984). The psychology of lineup identifications. Journal of Applied Social Psychology, 14, 89-103.

Wells, G. L., Lindsay, R. C. L., \& Ferguson, T. J. (1979). Accuracy, confidence, and juror perceptions in eyewitness identification. Journal of Applied Psychology, 64, 440-448.

\section{NOTES}

1. Although questionnaires were mailed to prosecutors in large and small cities, with the intent to sample large and small population centers, this plan may have been partially thwarted by the fact that the actual size of a prosecutor's district may be unrelated to the size of the city in which his/her office is located. For example, Annapolis, Maryland, is a city of about 32,000 people, but the DA who is located in Annapolis has jurisdiction over all of Anne Arundel County, which has a population of more than 370,000 people.

2. In an earlier survey of all judges in Missouri, the median ratio of EW cases to total criminal cases was $2.7 \%$. The range of replies, as was found with the prosecutors' estimates, was quite large (from $0 \%$ to more than $40 \%$ ). Consider that judges' estimates represent the frequency of both trials and hearings in which eyewitness testimony was important. Loh (1981) estimated that eyewitness evidence is used in only $5 \%$ of all criminal trials. Estimates vary, but between $5 \%$ and $10 \%$ of all arrest cases go to trial. If that figure is correct, then about 193,282 criminal trials $(2,577,100 \times 7.5 \%)$ take place every year and $5 \%$ of those, or 9,664 trials, involve eyewitness testimony.

3. Keep in mind that "annual arrest figures do not measure the number of individuals arrested since one person may be arrested several times during the year for the same or different offenses" (Uniform Crime Reports for the United States, 1987, p. 163).

4. Several "big city" public defenders disagree with the findings; they suggest the ratio of eyewitness cases to felony cases is at least $30 \%$-i.e., 10 times what we have reported.

(Manuscript received March 14, 1988.) 